\title{
Imunophenotypic Evaluation as a Tool for Monitoring Risks for Blood Malignancies in Gas Station Workers
}

\author{
Fabio Santiago ${ }^{1,2 *}$, Simone Lima ${ }^{1,2}$, Susani Antunes ${ }^{1}$, Rafaele Tavares Silvestre ${ }^{1,2}$, \\ Luciano Rios Scherrer ${ }^{3}$, Gilda Alves ${ }^{1,2}$, Marilza de M Ribeiro- Carvalho ${ }^{1}$, Maria \\ Helena Ornellas ${ }^{1,2}$
}

\begin{abstract}
Background: Gas station workers are exposed to carcinogenic substances with impact on the hematologic and immune systems. The aim was to apply the immunophenotyping as a tool in the biological monitoring. Methods: This is a workplace-based case-control study with 49 workers and 26 controls. Medical interviews, hematological exams, and immunophenotyping analyses were performed. According to risk behavior (cleaning flannel and mistrust in the automatic fuel supply) the workers were divided into two groups: low risk (group 1) and high risk (group 2). Results: The results showed that CD16, HLA-DR, CD25, CD56+, CD16 CD56 low, and CD56 high expressions were higher in workers when compared to the control group $(\mathrm{P}=0.020, \mathrm{P}=0.001, \mathrm{P}=0.001 ; \mathrm{P}=0.034, \mathrm{P}=0.023$, and $\mathrm{P}=0.008$, respectively). The expressions of $\mathrm{CD} 2, \mathrm{CD} 8, \mathrm{CD} 10, \mathrm{CD} 81$ ow, and $\mathrm{CD} 4 / \mathrm{CD} 8$ ratios were lower $(\mathrm{P}=0.016, \mathrm{P}=0.001$, $\mathrm{P}=0.001, \mathrm{P}=0.017, \mathrm{P}=0.0259$, and $\mathrm{P}=0.029$, respectively). Headache and paresthesia complaints were associated with workers when compared to the control group (OR $=4.091,95 \% \mathrm{CI}, 1.400-11.951, \mathrm{P}=0.014 ; \mathrm{OR}=12.12,95 \%$ $\mathrm{CI}, 1.505$ - 97.61, $\mathrm{P}=0.004)$. Using cleaning flannel and mistrust in the automatic fuel supply (risk behaviors) were associated with group $2(\mathrm{OR}=9.71,95 \% \mathrm{CI}, 2.60-36.26, \mathrm{P}=0.005 ; \mathrm{OR}=18.18,95 \% \mathrm{CI}, 2.04-161.37, \mathrm{P}=0.004)$. Conclusions: The results strengthen the worker's immunosuppression hypothesis, which may contribute to some disorders and the carcinogenesis process. The evaluation of the immune system by flow cytometry is a promising tool for monitoring blood malignancy risk in addition to regular classic hematological exams.
\end{abstract}

Keywords: Flow cytometry- lymphocyte phenotype- occupational exposure- human health risk assessment

Asian Pac J Cancer Prev, 20 (7), 2109-2115

\section{Introduction}

In Brazil, according to recent (2019) personal communication with a union representative, there are about 500,000 gas station workers, $20 \%$ of whom are females. They are chronically exposed to fuel vapors that contain established human carcinogens, such as BTEX (benzene, toluene, ethylbenzene, and xylenes) (Moura-Correa et al., 2014). According to IARC, benzene is considered the main carcinogenic agent (group 1 according to IARC), and the association with hematological diseases such as lymphoblastic leukemia (ALL), chronic lymphocytic leukemia (CLL), myelodysplastic syndromes (MDS), and myelogenous leukemia (AML), as well as different forms of non-Hodgkin's lymphoma (NHL), has become clearer over the years (IARC, 2014; Stenehjen et al., 2015; Rushton et al., 2014; Schnatter et al., 2012).

MDS and AML are the most frequent malignant neoplasms associated with BTEX exposure In addition there are evidences of the relationship between benzene and other types of hematological diseases such as other leukemias, lymphomas and multiple myeloma (De Roos et al., 2018). It is well known that severe bone marrow dysplasia is frequently accompanied by early alterations in the immune system and in peripheral cell subsets (Schnatter et al., 2012). The bone marrow injury by BTEX metabolites is a predisposing event in the pathogenesis of BTEX-induced hematopoietic disease (Smith, 2010). Thus, the early identification of this condition and cautioning the gas station workers about this risk may prevent the hematological disease progression.

The immunophenotyping by flow cytometry is currently one of the fundamental pillars for the diagnosis and classification of lymphoproliferative and myeloid diseases (Craig and Foon, 2009). Immunologic dysregulation can be one cause of these diseases (Davidson-Moncada et al., 2018). The aim of the present study is to apply immunophenotyping as a tool in the biological monitoring 
of the gas station workers, helping in the diagnosis of benzene poisoning and in the prevention of hematological diseases.

\section{Materials and Methods}

\section{Population study}

A total of 75 subjects were included in this study. The exposed group consisted of 49 workers ( 7 males and 42 females) recruited from 5 gas stations in the city of Rio de Janeiro. Gas stations were selected in a non-random way, seeking the ones with a larger number of women who could be more affected by BTEX exposure than men (Santiago et al., 2014; Santiago et al., 2017). In the control group a total of 26 unexposed subjects ( 9 males and 17 females) were selected among our university employees (professors and administrative staff) and students. This study was approved by the local ethics committee at the University of Rio de Janeiro State-UERJ (34310014.9.0000.5259/14)/ Brazil, and all subjects were informed about the potential benefits and risks of this study.

Participation was voluntary and written informed consent was obtained from each participant in both groups. A physician questioned the members of the study population regarding their age, sex, race, life-style (smoking habits, alcohol and illicit drug consumption, etc.), and medical and work histories.

Classic hematological exam and biochemistry analysis

The hematological analysis consisted of hemogram and biochemistry analyzes. All blood tests were performed in the central laboratory of HUPE (Pedro Ernesto University Hospital), according to standard hematological methods.

\section{Immunophenotyping}

Two mL of EDTA-treated peripheral blood was prepared within 2 hours after collection using 18 antibodies (CD2, CD3, CD4, CD5, CD7, CD8, CD10, CD11c, CD16, CD19, CD22, CD20, CD25, CD27, CD45, CD56, and HLA-DR), according to standard procedures (Stelzer et al., 1997). The samples/antibodies were incubated for 30 min. The red cells were lysed with lysing solution (FACS Lysing Solution - Becton Dickinson). After being lysed, each sample was centrifuged twice, at $1000 \mathrm{rpm}$ for $5 \mathrm{~min}$. The cells were resuspended in $200 \mu \mathrm{L}$ of phosphate saline buffer (PBS - 0.01M, pH 7.4-7.6). The BD FACSCanto II cytometer was used and the data analyses were performed using the Infinicyt ${ }^{\circledR}$ software. The acquisition and analysis of immune-marked cells were standardized for 100,000 events per sample. Percentages were obtained for each lymphocyte sub-population and the absolute numbers of the lymphocyte sub-populations were also calculated.

\section{Statistical analysis}

The workers were divided in two groups depending on BTEX exposure: group 1 with low risk and group 2 with high risk. The high risk of benzene poisoning was established based on the Brazilian Ministry of Health and the US Department of Labor guidelines for benzene poisoning diagnosis, using the following criteria:

(1) Number of leucocytes lower than 4,000 and/or neutrophils lower than 2,000; or anemia (low hematocrit: $40 \%$ for men and $36 \%$ for women); or thrombocytopenia (lower than 150,000);

(2) Report of four or more medical complaints (weight loss, weakness, dizziness, drowsiness, headache, irritability, nervousness, anxiety, insomnia, change of mood, depression, attention alteration, memory change, paresthesia, involuntary movements, tremor, and decreased muscle strength) related to benzene intoxication.

The groups were compared according to clinical characteristics, risk behaviors at work, classic hematological exams, and the immunophenotyping results. A non-parametric Mann-Whitney or Kruskall-Wallis test was used for comparison of the distributed variables between the groups. Also, the Pearson's Chi-square or Fisher's exact test was used to test the statistical significance of the association between clinical variables. The Predictive Analytics Software (PASW-Version 18) was used, and for all statistical tests $\mathrm{P}<0.05$ was considered significant.

\section{Results}

\section{Clinical findings and health report}

The gas station attendants routinely worked for 6 days per week, for 8 hours or more per day. The worker's median age (group 1 and group 2) was 33.2 years, with 7.9 years of mean BTEX exposure time. The comparative analysis between the total of gas station workers and the control group for smoking, illicit drug consumption, alcohol consumption, and gender showed no significant $P$ values (Table 1); thus, the comparative analysis of the data was performed without taking these variables into account.

In the medical inquiries, anxiety $(63.3 \%)$ was the most reported complaint, followed by headache $(55.1 \%)$, irritability $(46.9 \%)$, drowsiness $(37.5 \%)$, paresthesia $(32.7 \%)$, and others. The comparative analysis between the total of workers and the control group for headache and paresthesia showed significant $\mathrm{P}$ values for both variables associated with the workers, according to the Chi-Square test applied to Odds Ratio (OR) analysis (OR $=4.091,95 \%$ CI, $1.400-11.951, \mathrm{P}=0.014$; OR $=12.12$, $95 \%$ CI, $1.505-97.61, \mathrm{P}=0.004$, respectively) (Table 1). Note that no subjects reported carrying neoplasm, immunodeficiency, or self-immunity diseases.

For the comparative analysis of classic hematological exam results and exposure time between the workers group and the control group, Table 2 was created. An increased female CHGM, typical lymphocytes, and monocyte counts were observed in gas station workers (groups 1 and 2) related to the control group according to Kruskall-Wallis test $(\mathrm{P}=0.016, \mathrm{P}=0.001$, and $\mathrm{P}=0.003$, respectively). In contrast, a decreased male hematocrit was found $(\mathrm{P}=0.015)$. Also, a higher gamma-glutamyltransferase (GGT) result was associated with group 1 compared to group 2, (average $=33.0$ and $\mathrm{P}=0.012$ ). Note that no more significant associations were found between groups 1 and 2 in classical hematological parameters independent of gender.

With regard to immunophenotyping data, we observed a higher expression of CD16, HLA-DR, CD25, CD56 + 
Table 1. Comparative Analysis of Demographic Data between Gas Station Workers and Control Group

\begin{tabular}{|c|c|c|c|}
\hline Biometric data & $\begin{array}{l}\text { Gas station } \\
\text { Group }\end{array}$ & $\begin{array}{c}\text { Control } \\
\text { Group }\end{array}$ & $\begin{array}{c}\text { P- } \\
\text { value }\end{array}$ \\
\hline Age (years) & $33.3( \pm 9.9)$ & $28( \pm 13.4)$ & 0.1 \\
\hline Gender & & & 0.129 \\
\hline Men & $7(14.3 \%)$ & $8(30.8 \%)$ & \\
\hline Women & $42(85.7 \%)$ & $18(69.2 \%)$ & \\
\hline Smokers & & & 1 \\
\hline Yes & $7(14.3 \%)$ & $3(11.5 \%)$ & \\
\hline No & $42(85.7 \%)$ & $23(88.5 \%)$ & \\
\hline Illicit drug consumption & & & 1 \\
\hline Yes & $3(6.1 \%)$ & $2(7.7 \%)$ & \\
\hline No & $46(93.9 \%)$ & $24(92.3 \%)$ & \\
\hline Drinking & & & 0.62 \\
\hline Yes & $30(63.8 \%)$ & $15(57.7 \%)$ & \\
\hline No & $17(36.2 \%)$ & $11(42.3 \%)$ & \\
\hline \multicolumn{4}{|l|}{ Symptoms } \\
\hline Weight Loss & $10(20.4 \%)$ & $5(19.2 \%)$ & 1 \\
\hline Weakness & $16(32.7 \%)$ & $3(32.7 \%)$ & 0.54 \\
\hline Dizziness & $15(32.6 \%)$ & $4(15.4 \%)$ & 0.16 \\
\hline Drowsiness & $18(37.5 \%)$ & $6(24.0 \%))$ & 0.3 \\
\hline Headache & $27(55.1 \%)$ & $6(23.1 \%)$ & 0.014 \\
\hline Irritability / Nervousness & $23(46.9 \%)$ & $7(26.9 \%)$ & 0.137 \\
\hline Anxiety & $31(63.3 \%)$ & $11(42.3 \%)$ & 0.093 \\
\hline Insomnia & $14(28.6 \%)$ & $3(11.5 \%)$ & 0.147 \\
\hline Change of mood / Depression & $14(28.6 \%)$ & $5(19.2 \%)$ & 0.419 \\
\hline Attention Alteration & $12(25.0 \%)$ & $5(19.2 \%)$ & 0,773 \\
\hline Memory change & $13(26.5 \%)$ & $4(14.4 \%)$ & 0.387 \\
\hline Paresthesia & $16(32.7 \%)$ & $1(3.8 \%)$ & 0.004 \\
\hline Involuntary movements & $4(8.2 \%)$ & $1(3.8 \%)$ & 0.653 \\
\hline Tremors & $8(16.3 \%)$ & $1(3.8 \%)$ & 0.15 \\
\hline Decreased muscle strength & $6(12.2 \%)$ & $0(0.0 \%)$ & 0.09 \\
\hline
\end{tabular}

The results in bold are considered statistically significant $P<0.05$

CD16, CD 56low, and CD 56high in lymphocytes in the workers (groups 1 and 2) compared to the control group $(\mathrm{P}=0.020, \mathrm{P}=0.001, \mathrm{P}=0.001 ; \mathrm{P}=0.034, \mathrm{P}=0.023$, and $\mathrm{P}=0.008$ respectively). In contrast, a lower expression of CD2, CD8, CD10, and CD8low was observed ( $\mathrm{P}=0.016$, $\mathrm{P}=0.002, \mathrm{P}=0.001$, and $\mathrm{P}=0.025$, respectively). No more significant expression alterations were observed; however, the lower CD4 / CD8 ratio in the total of gas station workers compared to the control group should be highlighted $(\mathrm{P}=0.029)$ (Table 2). Figure 1 shows the immunophenotyping analysis of one female gas station worker who had alteration in the $\mathrm{CD} 4 / \mathrm{CD} 8$ ratio and $\mathrm{NK}$ cell expression.

However, no significant association was found between groups 1 and 2 in monoclonal antibody results. To compare the variables of risk behaviors adopted by the workers between the groups, Chi-square tests were applied to Odds Ratio (OR) analysis of cleaning flannel use and mistrust in the automatic fuel supply (automatic pump device that stops the fuel supply when filling the car's tank). The results revealed a significant effect of these risk behaviors on the workers in group $2(\mathrm{OR}=9.71,95 \% \mathrm{CI}$,
2.60-36.26, $\mathrm{P}=0.005 ; \mathrm{OR}=18.18,95 \% \mathrm{CI}, 2.04-161.37$, $\mathrm{P}=0.004$, respectively) (Table 3 ).

\section{Discussion}

In Brazil there is no self-service system of fuel and the female labor force at gas stations has been increasing exponentially in the last few years in our country. This is the reason for the interest focusing on the health of female gas station workers. A purposeful female predominance among young workers was observed, with 7.9 years of mean time exposure and a median age of 33.3 years.

According to the Brazilian Ministry of Health and the US Department of Labor, the diagnosis of benzene poisoning is clinically performed by an eminent physician and based on classic hematological exams (Brasil. Ministério da Saúde, 2016; Occupational Safety and Health Administration). With regard to symptoms, we observed a higher prevalence of many medical complaints, with statistical significance for headaches and paresthesia. Although Mitri et al., (2015) and Alves et al., (2017) reported similar symptoms in Brazilian gas station workers, in both studies there were no control groups to compare and assure the relevance of the reported data. In Alves et al., (2017) it was not clear whether workers were evaluated by a physician, as recommended by National and International Health Agencies.

It is worth noting that significant decreases in $\mathrm{WBC}$, $\mathrm{RBC}$, and platelet counts, and even the presence of isolated thrombocytopenia, have already been observed in human populations exposed to high levels of benzene in classic hematological exams (Abou-El Wafa et al., 2015; Smith, 2010). Abou-ElWafa et al.,(2015) reported a mean RBC count, hemoglobin level, and HCT significantly lower in gas station workers compared to the control group. In our study we found a range of cell alterations in classic hematological exams (female CHGM, typical lymphocytes, monocytes, male hematocrit), evidencing a non-specific cell effect and the clear involvement of the myeloid and lymphoid cell sets by BTEX exposure.

It is well known that all leukemias and MDS arise in the stem and progenitor cells of the bone marrow, which in chronic benzene exposure are clearly damaged by release of reactive oxygen species (ROS) produced by hydroquinone (benzene metabolite) oxidation reaction (Stenejjem et al., 2015). It is believed that the mechanisms of xylenes, toluene, and ethyl benzene-induced myelotoxicity are very similar to benzene, but this is still unclear (Smith, 2014). Also, it is well known that autoimmune alterations caused by initial bone marrow injury is an early or predisposing event in the pathogenesis of benzene-induced persistent hematopoietic disease.

With regard to immunophenotyping results, the increase in NK (CD56+CD16) cells recorded among BTEX workers was somewhat puzzling, especially considering the concomitant increase in CD 25 (IL-2) and DR + cells, known as markers of activation of the immune system. Although the increase in NK cells would be inconsistent with immunosuppressive activity by BTEX, similar results were found by Bergamaschi et al., 
Table 2. Comparative Analysis of Classic Hematological Exam and Immunophenotyping Results and Exposure Time between the Gas Station Workers and the Control Group

\begin{tabular}{|c|c|c|c|c|}
\hline & Group 1 & Group 2 & Control group & p-value \\
\hline Mean exposure time (year) & $9.31( \pm 7.94)$ & $7.17( \pm 6.27)$ & $\longrightarrow$ & 0.373 \\
\hline \multicolumn{5}{|l|}{ Blood test } \\
\hline Platelets $(\mathrm{mil} / \mu \mathrm{L})$ & $256.7( \pm 66)$ & $286.4( \pm 71.3)$ & $272.5( \pm 55.6)$ & 0.282 \\
\hline Leukocytes $(/ \mu \mathrm{L}$ & $8425( \pm 2602)$ & $6816( \pm 2094)$ & $7532( \pm 1577)$ & 0.144 \\
\hline Neutrophils (\%) & $56.29( \pm 8.60)$ & $54.67( \pm 13.22)$ & $60.53( \pm 9.12)$ & 0.196 \\
\hline Eosinophils (\%) & $3.30( \pm 3.54)$ & $2.66( \pm 2.12)$ & $2.99( \pm 4.99)$ & 0.171 \\
\hline Basophils (\%) & $0.49( \pm 0.53)$ & $0.33( \pm 0.25)$ & $0.43( \pm 0.53)$ & 0.468 \\
\hline Granulocytes (\%) & $2.06( \pm 2.20)$ & $1.50( \pm 1.21)$ & $2.56( \pm 2.7)$ & 0.064 \\
\hline Typical lymphocytes (\%) & $32.96( \pm 10.88)$ & $32.40( \pm 12.60)$ & $23.51( \pm 6.07)$ & 0.001 \\
\hline Monocytes (\%) & $6.48( \pm 1.95)$ & $6.00( \pm 2.16)$ & $4.73( \pm 1.37)$ & 0.003 \\
\hline Gamma-GT (U/L) & $33.04( \pm 20.38)$ & $21.32( \pm 8.52)$ & $21.20( \pm 12.06)$ & $0.012 *$ \\
\hline \multicolumn{5}{|l|}{ Women } \\
\hline Hemoglobin & $13.10( \pm 1.24)$ & $12.73( \pm 1.36)$ & $12.99( \pm 0.65)$ & 0.63 \\
\hline Hematocrit (\%) & $38.92( \pm 3.16)$ & $38.23( \pm 4.10)$ & $39.7( \pm 1.55)$ & 0.09 \\
\hline HGM (fl) & $29.4( \pm 2.02)$ & $29.08( \pm 1.80)$ & $32.68( \pm 15.58)$ & 0.768 \\
\hline CHGM (g/dL) & $33.64( \pm 0.97)$ & $33.29( \pm 0.94)$ & $32.67( \pm 0.95)$ & 0.016 \\
\hline $\mathrm{VCM}$ & $87.33( \pm 4.59)$ & $87.32( \pm 4.88)$ & $87.67( \pm 4.37)$ & 0.981 \\
\hline \multicolumn{5}{|l|}{ Men } \\
\hline Hemoglobin & $14.82( \pm 0.45)$ & $\longrightarrow$ & $14.76( \pm 2.03)$ & 0.183 \\
\hline Hematocrit (\%) & $43.6( \pm 1.233)$ & & $44.3( \pm 6.78)$ & 0.015 \\
\hline HGM (fl) & $29.4( \pm 2.02)$ & & $32.68( \pm 15.58)$ & 0.768 \\
\hline CHGM (g/dL) & $34.01( \pm 0.88)$ & $\longrightarrow$ & $33.46( \pm 1.21)$ & 0.298 \\
\hline VCM & $86.63( \pm 3.18)$ & $\longrightarrow$ & $84.83( \pm 3.26)$ & 0.418 \\
\hline $\mathrm{CD} 2$ & $76.16( \pm 19.80)$ & $81.37( \pm 9.57)$ & $85.84( \pm 3.71)$ & 0.016 \\
\hline CD3 & $73.93( \pm 6.91)$ & $76.43( \pm 9.63)$ & $77.63( \pm 7.67)$ & 0.344 \\
\hline CD4 & $46.61( \pm 10.21)$ & $44.90( \pm 7.26)$ & $42.06( \pm 12.33)$ & 0.221 \\
\hline CD8 & $22.08( \pm 6.50)$ & $24.06( \pm 6.76)$ & $31.63( \pm 5.90)$ & 0.002 \\
\hline CD 8 low & $7.48( \pm 4.61)$ & $6.91( \pm 2.95)$ & $11.13( \pm 5.65)$ & 0.025 \\
\hline $\mathrm{CD} 4 / \mathrm{CD} 8$ & $2.27( \pm 0.80)$ & $2.00( \pm 0.64)$ & $3.97( \pm 6.46)$ & 0.029 \\
\hline $\mathrm{CD} 4+\mathrm{CD} 8$ & $0.92( \pm 0.83)$ & $0.77( \pm 0.51)$ & $0.66( \pm 0.48)$ & 0.809 \\
\hline CD5 & $71.62( \pm 10.21)$ & $70.02( \pm 9.61)$ & $73.98( \pm 0.397)$ & 0.397 \\
\hline CD7 & $73.95( \pm 13.49)$ & $73.99( \pm 13.80)$ & $75.91( \pm 10.18)$ & 0.905 \\
\hline CD10 & $0.79( \pm 1.20)$ & $1.45( \pm 4.16)$ & $1.52( \pm 1.20)$ & 0.001 \\
\hline CD11c & $76.21( \pm 33.36)$ & $78.69( \pm 27.10)$ & $92.69( \pm 3.36)$ & 0.811 \\
\hline CD16 & $10.31( \pm 6.15)$ & $7.43( \pm 7.32)$ & $12.09( \pm 28.58)$ & 0.02 \\
\hline CD56 & $16.15( \pm 8.62)$ & $14.09( \pm 8.69)$ & $11.36( \pm 5.64)$ & 0.178 \\
\hline CD56 low & $14.66( \pm 8.24)$ & $12.95( \pm 7.87)$ & $7.85( \pm 6.45)$ & 0.023 \\
\hline CD56 high & $3.60( \pm 5.73)$ & $2.69( \pm 4.22)$ & $1.31( \pm 2.63)$ & 0.008 \\
\hline $\mathrm{CD} 16+\mathrm{CD} 56$ & $8.29( \pm 6.02)$ & $6.13( \pm 5.13)$ & $5.23( \pm 7.41)$ & 0.034 \\
\hline NKT & $3.75( \pm 4.57)$ & $4.21( \pm 3.50)$ & $6.20( \pm 6.20)$ & 0.238 \\
\hline CD19 & $10.08( \pm 5.73)$ & $10.51( \pm 4.81)$ & $8.23( \pm 4.04)$ & 0.285 \\
\hline $\mathrm{CD} 20$ & $9.66( \pm 5.39)$ & $10.90( \pm 4.59)$ & $9.37( \pm 3.45)$ & 0.417 \\
\hline CD22 & $10.83( \pm 5.48)$ & $11.40( \pm 4.28)$ & $9.58( \pm 3.19)$ & 0.28 \\
\hline CD25 & $8.91( \pm 8.71)$ & $6.03( \pm 6.83)$ & $1.66(1.19)$ & 0.001 \\
\hline $\mathrm{CD} 27$ & $52.77( \pm 10.39)$ & $52.62( \pm 13.97)$ & $72.16(25.92)$ & 0.059 \\
\hline HLA-DR & $13.47( \pm 5.92)$ & $16.38( \pm 7.92)$ & $11.74(4.29)$ & 0.04 \\
\hline
\end{tabular}

The results in bold are considered statistically significant , $\mathrm{P}<0.05$. *This was the only variable showing statistical difference between group 1 and group 2. 
Table 3. Association between Risk Behavior of Gas Station Workers between Groups 1 and 2

\begin{tabular}{lccccc}
\hline Risk behavior at work & Group 1 & Group 2 & P-value & Odds Ratio & 95\% CI Odds Ratio \\
\hline Uses the cleaning flannel & $7(29.2 \%)$ & $20(80 \%)$ & $\mathbf{0 . 0 0 1}$ & 9.714 & $2.602-36.264$ \\
Smells the fuel cap before refueling & $2(9.5 \%)$ & $6(28.6 \%)$ & 0.238 & 3.8 & $0.669-21,598$ \\
Holds the face close when fueling to the limit & $11(52.4 \%)$ & $8(38.1 \%)$ & 0.536 & 0.559 & $0.164-1.911$ \\
Mistrust in the automatic fuel supply & $1(4.8 \%)$ & $10(47.6 \%)$ & $\mathbf{0 . 0 0 4}$ & 18.182 & $2.048-161.37$ \\
Aspirates fuel with the mouth (hose) & $6(28.6 \%)$ & $7(33.3 \%)$ & 1 & 1.25 & $0.337-4.639$ \\
Wet clothes with fuel & $9(42.9 \%)$ & $10(47.6 \%)$ & 1 & 1.212 & $0.359-4.092$ \\
\hline
\end{tabular}

The results in bold are considered statistically significant, $P<0.05$.
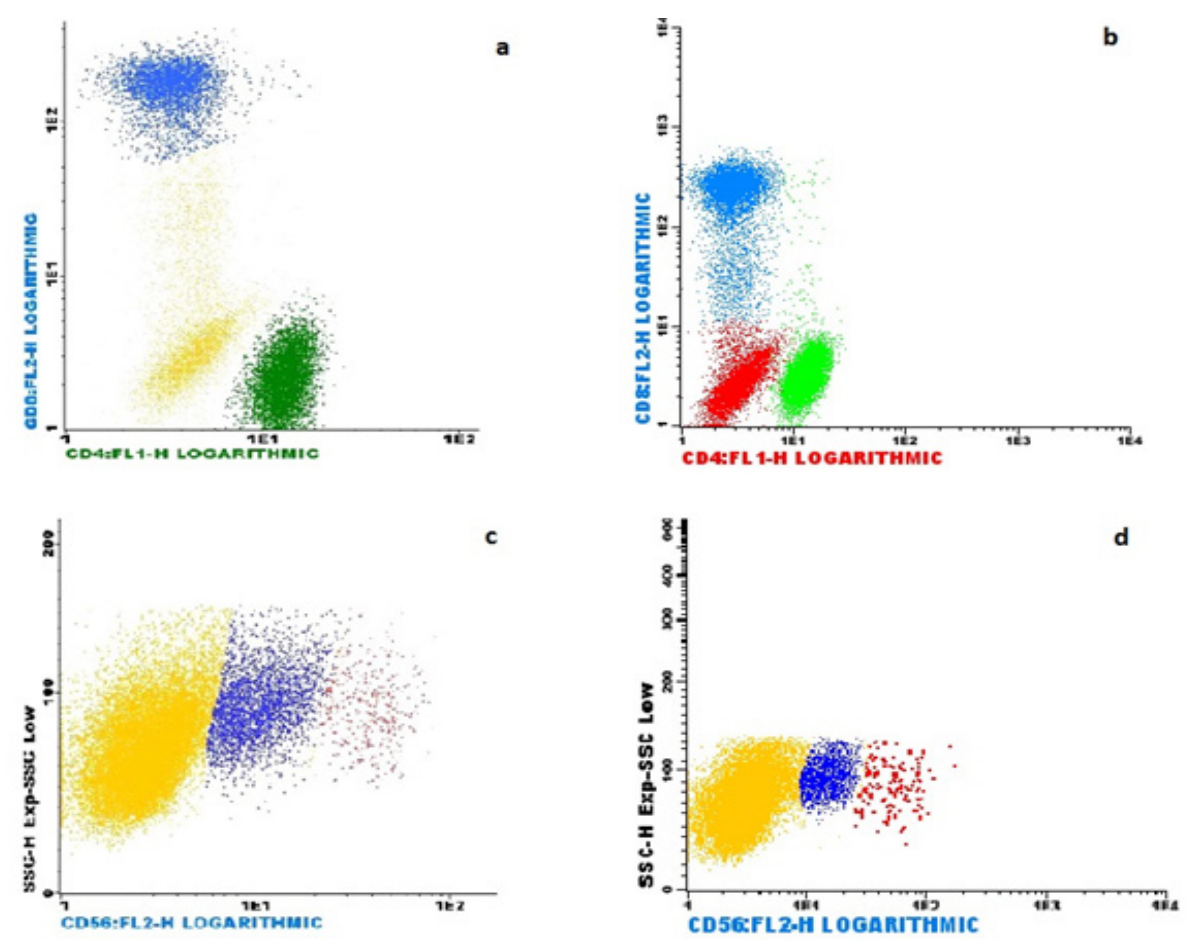

Figure 1. a, Shows the CD4 (35.54\%) and CD8 (22.27\%) cell expression of one female gas station worker, who has a low CD4 / CD8 ratio (1.59). In green the CD4 cells and in blue the CD 8 cells observed in the lymphocyte gate; b, Shows the CD4 (45.67\%) and CD8 (24.57\%) cell expression of one female control, who has 1.86 of CD4 / CD8 ratio. In green the CD4 cells and in blue the CD 8 cells observed in the lymphocyte gate; c, The flow cytometric analyses of NK cells (CD16 and CD56 positive) found in the lymphocyte gate of one female gas station worker. A high expression of NK cells with $17.14 \%$ of CD56 LOW (blue) and $2.46 \%$ of CD56 HIGH (red) was observed; d, The flow cytometric analyses of NK cells (CD16 and CD56 positive) found in the lymphocyte gate of one control female. Was observed a expression of NK cells with $2.38 \%$ of CD56 LOW (blue) and $0.23 \%$ of CD56 HIGH (red).

(1995), who studied the expression and activity of NK cells in workers exposed to styrene. Despite Bergamaschi et al.,'s findings (2015) of an increase in phenotypic NK cells (CD56+CD16), CD25, and DR + cells, they proved a lower lytic activity by these NK cells in the exposed group. In agreement with this finding, Santiago et al., (2017) described a rare type of NK cells (NK bright) in peripheral blood of two Brazilian female gas station workers. This type of NK cells is known to have a low lytic activity with a high expression of cytokine. Note that CD25 ( $\alpha$ chain of IL-2R) induces the activation and proliferation of not only NK cells, but also T cells, thymocytes, B cells, and macrophage populations. CD25 high expression in myelodysplastic syndrome may precede acute myeloid leukemia and chronic myeloid leukemia (Bergamaschi et al., 1995). Given the discrepancy with the above findings pointing to immunosuppression, the increase in CD25 and DR could be envisaged either as an unspecific response or as a compensatory mechanism in response to the low cell proliferations caused by BTEX exposure.

In agreement with the workers' immunosuppression hypothesis, a low CD4/CD 8 ratio was observed compared to the control group. This low ratio indicates a disproportion of $\mathrm{T}$ helper (CD4) and $\mathrm{T}$ suppressor (CD8) lymphocytes, as observed in patients with severe immunosuppression, such as in AIDS patients. It should also be noted that in MDS patients this ratio is frequently inverted, and there is an increase in cytotoxic CD8+ T cells (CTL) as well (Nakase et al., 2017).

It should be noted that none of the classic hematological exam and immunophenotyping results was associated with either group ( 1 or 2 ) of workers. Thus, we questioned the guidelines adopted for benzene poisoning diagnosis based only on the symptomatology and classic hematological exams, since innumerable alterations were found when comparing the data between the control group and the total of gas station workers. However, it is worth noting that the GGT results were associated with group 1, with 
less medical complaints. Liu et al., (2009) suggest that GGT within its reference range predicts several clinical outcomes as a sensitive marker of oxidative stress in humans and can mark exposure to various environmental pollutants. Epidemiological findings about GGT serum imply the possibility of harmful effects of various environmental pollutants at background levels currently regarded as safe.

Note that the use of cleaning flannel and the mistrust in the automatic fuel supply by the workers were associated with group 2, with the highest medical complaints. The cleaning flannel wet with fuel remains most of the time on the attendants' shoulder, and the workers who mistrust the automatic fuel supply hold their face close to the fuel tank to hear or to see the gasoline rising when fueling the car, thereby increasing the BTEX exposure. Thus, the workers' orientation regarding the non-adoption of these behaviors would reduce their symptoms and possibly the carcinogenic effects.

In conclusion in agreement with the immunosuppression hypothesis of these workers, a range of changes were found in CD16, HLA-DR, CD25, CD56+CD16, CD56 high, CD56 low, CD2, CD8, CD8 low, and CD10 expression, as well as a low CD4/CD8 ratio compared with the control group. Not only were risk behaviors at work (the use of cleaning flannel and mistrust in the automatic fuel supply) identified and associated with high risk of benzene poisoning, but also the results indicated that workers exposed to BTEX have their immune system impaired, which may contribute to some disorders and the carcinogenesis process. The evaluation of the immune system by flow cytometry is a promising tool in the blood monitoring of these workers in addition to normal classic hematological exams. The BTEX poisoning diagnosis and the carcinogenesis process identification are impaired when we take into account only the medical complaints/ symptomatology and the classic hematological exam results.

Unfortunately, the toxicological assessment studies of gas station workers are still insufficient to fulfill the demand of these workers and the identification of the real risks. Further studies are needed, especially those related to the biological monitoring and the immune system of gas station workers.

\section{Acknowledgements}

We thank the subjects who volunteered for the study.

\section{Declarations}

\section{Authors'contributions}

MHO, GA, and FS designed the study and applied for Research Ethics Board approval. FS, RS, and SA recruited the workers. The immunophenotypic data were analyzed by MC, FS, and SL. FS and SL prepared the manuscript draft with important intellectual input from GA and MHO. All authors approved the final manuscript and had complete access to the study data.

\section{Competing interests}

The authors declare that they have no competing interests.

Availability of data and materials

All the data supporting our findings are contained within the manuscript.

\section{Consent for publication}

Written informed consents were obtained from all subjects for publication of this paper and any accompanying images.

\section{Ethics approval}

This study was approved by the Universidade of Rio de Janeiro State - UERJ (34310014.9.0000.5259/14), Brazil.

\section{Grant support}

Fundação de Amparo a Pesquisa do Rio de Janeiro (FAPERJ), APQ1 E.26/010.002022/2015.

\section{References}

Abou-ElWafa HS, Albadry AA, El-Gilany AH, Bazeed FB (2015). Some biochemical and hematological parameters among petrol station attendants: A comparative study. Biomed Res Int. 2015, 418724.

Alves LP, Vieira DSP, Nunes LSS, et al (2017). Relationship between symptoms, use of PPE and habits related to occupational exposure to BTEX compounds in workers of gas stations in Bahia, Brazil. J Environ Prot, 8, 650-61.

Bergamaschi E, Smargiassi A, Mutti A, Franchini I, Lucchini R (1995). Immunological changes among workers occupationally exposed to styrene. Int Arch Occup Environ Health, 67, 165-71.

Brasil. Ministério da Saúde. Secretaria de Atenção à Saúde. Departamento de Ações Programáticas Estratégicas. Risco químico: atenção à saúde dos trabalhadores expostos ao benzeno. Brasília: Ministério da Saúde; 2006. Disponível em: http://bvsms.saude.gov.br/ bvs/publicacoes/risco_ saude trabalhadores expostos benzeno.pdf

Craig FE, Foon KA(2008). Flow cytometric immunophenotyping for hematologic neoplasms. Blood, 111, 3941-67.

Davidson-Moncada J, Viboch E, Church SE, Warren SE, Rutella S (2018). Dissecting the immune landscape of acute myeloid leukemia. Biomedicines, 25, pii: E110.

IARC (2014) International Agency for Research on Cancer: agents classified by the IARC monographs, Vol. 1-109. IARC monographs on the evaluation of the carcinogenic risks to humans. IARC: Lyon, France, updated 14 January 2014. Available from: http://monographs.iarc.fr/ENG/ Classification/ ClassificationsAlphaOrder.pdf (accessed 1 March 2014).

Liu J, Drane W, Liu X, Wu T (2009). Examination of the relationships between environmental exposures to volatile organic compounds and biochemical liver tests: application of canonical correlation analysis. Environ Res, 109, 193-9.

Mitri S, Fonseca AS, Otero UB, et al (2015). Metabolic polymorphisms and clinical findings related to Benzene poisoning detected in exposed Brazilian Gas-Station workers. Int J Environ Res Public Health, 12, 8434-47.

Moura-Correa MJ, Jacobina AJR, Santos SAD, et al (2014). Exposição ao benzeno em postos de revenda de combustíveis no Brasil: Rede de Vigilância em Saúde do Trabalhador (VISAT). Ciênc Saúde Coletiva, 19, 4637-48.

Nakase K, Kita K, Kyo T, Katayama N (2017). High expression of interleukin-2 receptor $\alpha$-chain (CD25) in myelodysplastic 
syndrome preceding acute myeloid leukemia and chronic myeloid leukemia in myeloid blast crisis. Leuk Lymphoma, 58, 1268-70.

Occupational Safety and Health Administration, US Department of Labor. Medical surveillance guidelines for Benzene. In: Occupational Safety and Health Standards. https:// www.osha.gov/pls/oshaweb/owadisp.show_document?p table=STANDARDS\&p_id=10045. Accessed 25 Oct 2016 . PMCID: PMC2680193.

Roos AJ, Spinelli J, Brown EB, et al ( 2018). Pooled study of occupational exposure to aromatic hydrocarbon solvents and risk of multiple myeloma. Occup Environ Med, 75, 798-806.

Rushton L, Schnatter AR, Tang G, et al (2014). Acute myeloid and chronic lymphoid leukaemias and exposure to low-level benzene among petroleum workers. Br J Cancer, 110, 783-7.

Santiago F, Alves G, Otero UB, et al (2014). Monitoring of gas station attendants exposure to benzene, toluene, xylene (BTX) using three-color chromosome painting. Mol Cytogenet, 7, 15-21.

Santiago F, Lima S. Pinheiro T, Silvestre RT, et al (2017). Benzene poisoning, clinical and blood abnormalities in two Brazilian female gas station attendants: two case reports. BMC Res Notes, 10, 52-7.

Stelzer GT, Marti G, Hurley A, et al (1997). US-Canadian consensus recommendations on the immunophenotypic analysis of hematologic neoplasia by flow cytometry: standardization and validation of laboratory procedures. Cytometry, 30, 214-30.

Schnatter AR, Glass DC, Tang G, Irons RD, Rushton L (2012) Myelodysplastic syndrome and benzene exposure among petroleum workers: an international pooled analysis. J Natl Cancer Inst, 104, 1724-37

Smith MT (2010) Advances in understanding benzene health effects and susceptibility. Ann Rev Pub Health, 31, 133-48.

Stenehjem JS, Kjærheim K, Bråtveit M, et al (2015). Benzene exposure and risk of lymphohaematopoietic cancers in 25,000 offshore oil industry workers. Br $J$ Cancer, 112, 1603-12.

\section{@ $(\mathbb{0} \otimes$}

This work is licensed under a Creative Commons AttributionNon Commercial 4.0 International License. 